\title{
Changing industry to continuous operations: Different strokes for different plants
}

\author{
DONALD I. TEPAS, DENNIS R. ARMSTRONG, MARTHA L. CARLSON, \\ JAMES C. DUCHON, ANDREW GERSTEN, and DANIEL V. LEZOTTE \\ Illinois Institute of Technology and Work Systems Research, Chicago, Illinois
}

\begin{abstract}
A survey method was designed to evaluate the effect of shift work on industrial workers and to develop recommendations for 7-day around-the-clock production work systems. A Work-Sleep Survey was then offered to 2,340 hourly and salaried workers at four plants. Each plant was in the rubber and plastic products industry and on 5-day around-the-clock operations using permanent shifts. Of the total workers, $90.38 \%$ responded to the survey. The results agree with the findings of a previous survey, offered to workers through their unions, using many of the same survey items. The plants were found to differ in worker demographics, habits, and preferences. This survey method is helpful as an aid for the design and evaluation of shift-work systems tailored to specific worker and plant requirements.
\end{abstract}

In a previous report, we reviewed a method for interacting with labor unions and administering a Work-Sleep Survey to workers (Gordon, Tepas, Stock, \& Walsh, 1979). The methodology was designed to identify and recruit Saint Louis area workers, through their labor unions, to serve in coordinated laboratory and field interview sessions examining the effects of shift work (Walsh, Gordon, Maltese, McGill, \& Tepas, 1979). Subsequent analyses of the data from these sessions demonstrated the reliability and validity of this Work-Sleep Survey methodology as well as some of the potential problems of shift work (Armstrong, Tepas, \& Moss, 1980; Tepas, 1982c; Tepas, Walsh, \& Armstrong, 1981; Tepas, Walsh, Moss, \& Armstrong, 1981).

In this paper, we describe an extension of Work-Sleep Survey methodology. The Work-Sleep Survey was expanded to gather additional information about worker habits and preferences; the expanded survey was offered to workers in plants as a way of gathering information to aid industry in considering changes in existing worksystem schedules. We follow our description of the extensions to the methodology with a review of our research. We focus on three questions: Are these survey methods acceptable to the work force? Do these survey methods yield data comparable to the data collected in our previous studies? Are there differences between plants that suggest that the shift-work system of a given plant should be tailored to the characteristics of that plant?

\section{PROBLEM}

The management of a Fortune 500 company with numerous production facilities decided to change a num-

D. I. Tepas is now at the Department of Psychology, U-20, University of Connecticut, Storrs, CT 06268. ber of plants from 5-day around-the-clock to 7-day around-the-clock operations. (This company is listed in the "rubber, plastics" industry code classification of the Fortune 500.) The impetus for this corporate decision appeared to be a combination of change in leadership, increase in demand for products, relative cost of labor and capital equipment, problems associated with the use of excessive overtime work, and a potential restructuring of some key market areas. Companies with this Fortune 500 industry code classification do not, as a rule, manifest a high return to investors.

The four plants of immediate concern are located in rural mid-America, in what management refers to as the "Bible-belt." In some cases, a high percentage of the work force consists of women. The change to 7-day operations was intended to increase corporate earnings, but the potential for a decrease in earnings as a result of a poor move to 7-day operations was a serious concern for many managers. Specifically, managers feared that the advantages of increased machine use might be negated by a decrease in human productivity. We were asked to recommend a shift-work system that would ensure productive 7-day continuous operations.

Our response to this inquiry was that the company should not anticipate a general solution to this shift-work problem; instead, specific recommendations should be made for each plant, dependent upon the characteristics of the workers employed, the nature of the work performed, the characteristics of the equipment used, the market for the product, and other factors. The company agreed with our proposals that: (1) we would only intervene in plants in which independent discussions with workers led us to conclude that a satisfactory level of worker cooperation was feasible; (2) the identity of individual workers, as well as the company, would not be revealed by us; (3) data would be collected only from volunteers giving informed consent; (4) the data collected 
would become the property of the investigators, available for scientific publication without further corporate approval, given a maintenance of confidentiality. As a result of this agreement, we were allowed to intervene at four plants during the following 12-month period.

\section{METHOD}

\section{Work-Sleep Survey}

The Work-Sleep Survey is a concise four-page questionnaire requesting information on perceived work characteristics, hours of work, sleep behavior, health, drug use, and related matters (Gordon et al., 1979). Part 2 for the Work-Sleep Survey was developed prior to the start of this project, as a result of questions developed during our analysis of data collected from a previous use of this survey and of laboratory and interview data. The Work-Sleep Survey Part 2 is also four pages long. This survey requests information on shift-work preferences, behavior on days off, eating behavior, job selection, and other matters. The last two pages are a slightly modified form of the Horne and Ostberg (1976) morningnesseveningness scale.

In addition to these two standard survey forms, a custom-designed 1- or 2-page survey, termed the WorkSleep Survey Part 3, was developed for each of the four plants. These survey items were suggested by workers and managers after their study of the first two surveys. Thus, workers in each plant were offered three surveys, a total of 9 or 10 pages, which took 40-50 min for most workers to complete.

\section{Procedure}

Although the specifics varied from plant to plant, activities were completed at each of the four plants in the order described below.

Meeting with management. The plant manager scheduled a group meeting with all management personnel whom he considered to be critical participants in making a transition to 7-day operations. At this meeting, these individuals were informed that our primary role was to study the human-factor elements of this transition. Also, an attempt was made to motivate managers to begin their own studies of any other elements (e.g., equipment maintenance and personnel costs) that must be considered. The methodology of survey administration and analysis was explained. Work-Sleep Survey Parts 1 and 2 were reviewed in detail, and suggested questions for Survey Part 3 were solicited.

Meeting with workers. Three of the four plants were unionized, so we met with the union committees. In the one nonunion plant, meetings were held with groups of hourly workers from each work shift. For all four plants, all or part of these meetings were held with no managers present. Workers were informed that our role was to study human factor elements and that management would consider the additional elements that must be evaluated in coming to a final decision. The methodology of the survey was explained, and Work-Sleep Survey Parts 1 and 2 were reviewed in detail. Again, suggested questions for
Survey Part 3 were solicited and discussed. Finally, workers were asked whether they thought their fellow workers would cooperate by completing the survey.

Survey Administration. After the customized WorkSleep Survey Part 3 was constructed and printed, the complete survey was offered to all salaried and hourly workers at 1-h meetings scheduled for all shifts. Workers were paid for this hour. At these meetings, the purpose of the survey was briefly explained and a plea was made for a high response rate. Workers were told that the survey was not a test or an election, but rather an aid in our preparing recommendations which would be only one part of the final decision process. We requested complete and accurate information, but the workers were also informed that answering any or all questions was completely voluntary. Respondents were required to sign a detachable informed consent sheet, but they were not required to place their names on the survey itself. Everyone was informed that the survey was to be returned directly to us, and that no person from the company would have access to individual respondent data or would be informed as to who completed the survey.

Computer printout access. Approximately 1 month after offering the survey, a computer printout of the group data from the entire plant was mailed to the plant and made available to both management and labor. This printout did not sort the data by shift or work group, but consisted simply of descriptive statistics of the data collected from the entire respondent group. The printout provided all parties with access to an initial view of the survey results.

Final report and recommendations. Within the month following the mailing of the printout, we made extensive additional sorts of the respondent data by various work groups, evaluated key variables, and prepared a written report of our findings and recommendations. An oral presentation of the report was made to both management and worker groups, questions were answered, recommendations discussed, and a written copy of the report was distributed to both management and labor.

\section{Respondents}

Total plant attendance on the survey days for the four plants was 2,340 . Of these, $2,115(90.38 \%$ overall) responded to some or all of the survey. The four plants were identified as Plants A, B, C, and D. Plant D had the lowest response rate $(76.2 \%)$.

From respondent data, 1,888 workers were classified as either hourly workers on permanent shifts or as salaried workers: 1490 were hourly workers and 398 were salaried. Hourly workers had a mean age of 34.1 years (range $=18$ to $66, \mathrm{SD}=10.6)$. Salaried workers had a mean age of 37.1 years (range $=19$ to $64, \mathrm{SD}=9.6$ ). Female workers constituted $31.1 \%$ of hourly and $25.9 \%$ of salaried workers.

\section{RESULTS}

A direct comparison of the data collected was made with data previously collected using the Work-Sleep Survey in our Saint Louis study (Tepas, Walsh, \& Armstrong, 


\section{IIUOFCED OR SEFARATED?}

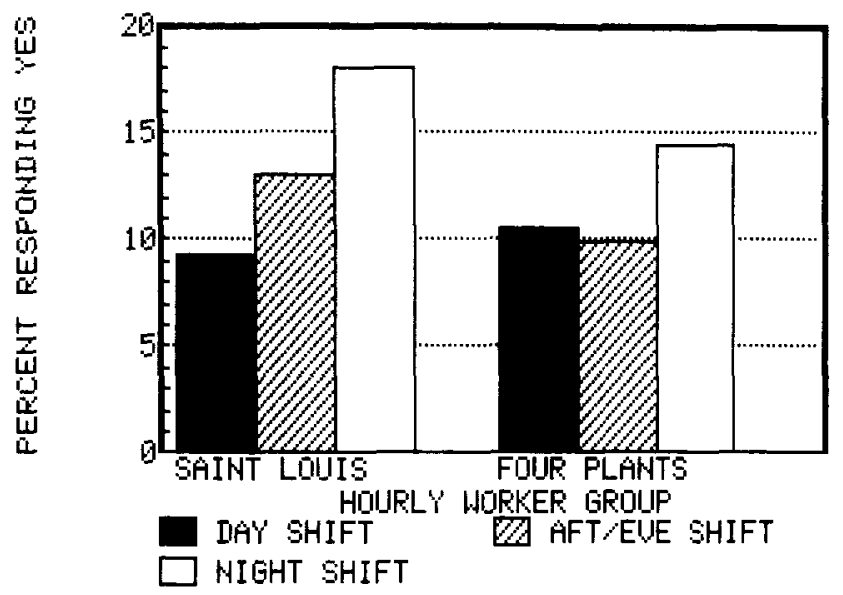

Figure 1. Percentage of hourly permanent shift workers on each shift in the Saint Louis and four-plant samples reporting that they were either separated or divorced.

1981) to determine whether the two methods of data collection yielded comparable data. To do this, the permanent-shift hourly workers were sorted, on the basis of their reported work hours, into three 8-hour permanent shift groups: day, afternoon/evening, and night shift workers. Data from these three groups of hourly workers were then compared with data from workers from the Saint Louis sample identified by the same shift criteria. The criteria for this shift classification are described in Tepas, Walsh, and Armstrong (1981).

\section{Comparison to Saint Louis Survey}

Age. The mean age of the hourly worker groups was calculated. The Saint Louis sample is $\mathbf{5 . 2 5}$ years older than the four-plant sample. For both samples, the dayshift workers are the oldest (approximately 40 years) and the night-shift workers are the youngest (34 years). For each of the three shift groups, the Saint Louis sample is older than the four-plant sample.

Sex of workers. The four-plant sample has a higher percentage of female workers in all shift groups (33\% overall). For both samples, the smallest percentage of female workers is on the afternoon/evening shift.

Marital status. Data from workers reporting that they were separated or divorced were collapsed. The results of this analysis are shown in Figure 1. For both samples, the percentage of hourly workers separated or divorced is highest for night-shift workers, with all the day- or afternoon/evening-shift groups reporting an incidence of divorce or separation that is lower than either night-shift grour.

Workday sleep length. Workers were asked to report the time of day during the workweek that they usually go to sleep and wake up. Sleep length was computed from these data and is presented in Figure 2. For both samples, night-shift workers reported the shortest sleep length and afternoon/evening-shift workers reported the longest sleep length.

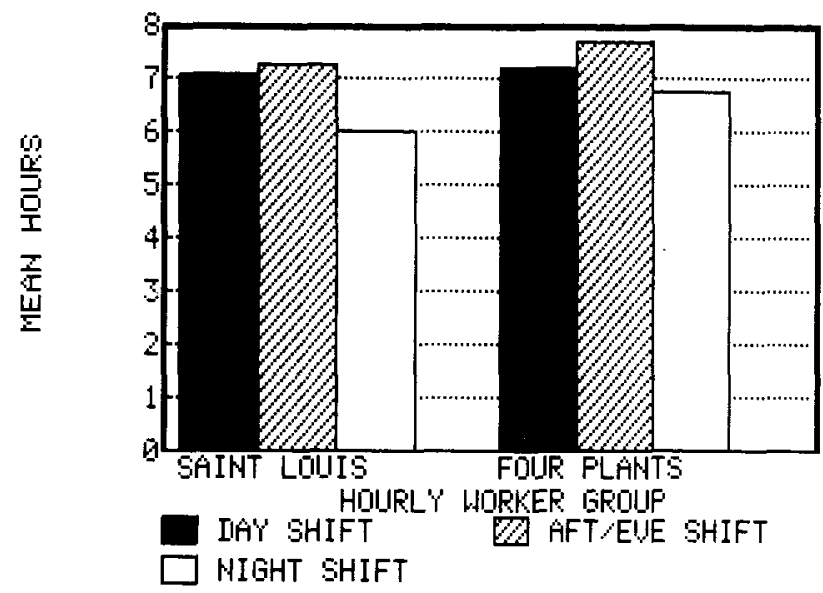

Figure 2. Mean reported workday sleep length in hours for permanent shift workers on each shift in the Saint Louis and four-plant samples.

Work-sleep phases. As a rule, day-shift workers sleep before work, whereas afternoon/evening- and night-shift workers sleep after work. The work and sleep times for all respondents were categorized to determine what percentage of the samples reported work-sleep strategies in keeping with this model: $95.8 \%$ of the Saint Louis sample and $94 \%$ of the four-plant sample reported behavior that matches this model.

Difficulty sleeping. The survey asked, "Do you often have difficulty in falling asleep or staying asleep?" For both samples, the percentage of workers responding "yes" to this question is highest for night-shift workers and lowest for day-shift workers. These data are presented in Figure 3. The incidence of affirmative response in the two night-shift groups is higher than that for any of the other groups.

\section{DIFFICILTY' SLEEFIHIS}

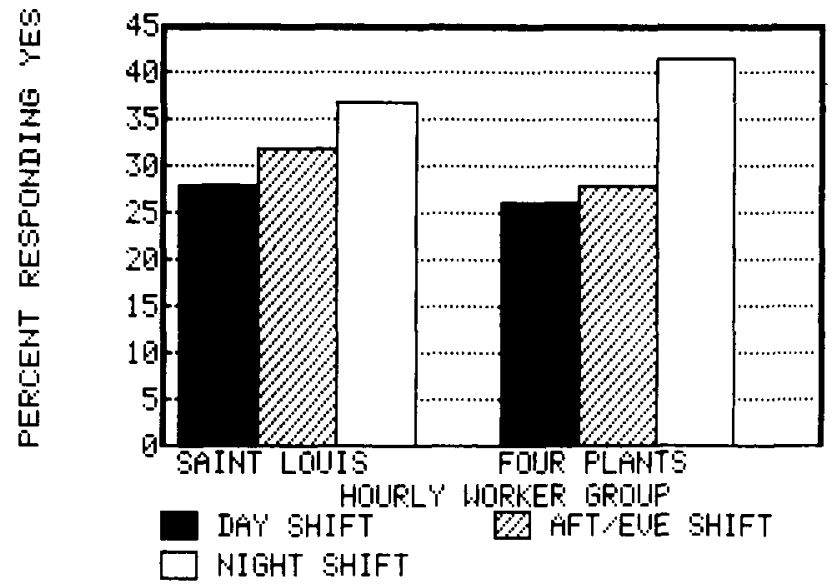

Figure 3. Percentage of hourly permanent shift workers on each shift in the Saint Louis and four-plant samples reporting difficulty in falling asleep or staying asleep. 
NAP DURING WORKLEEK

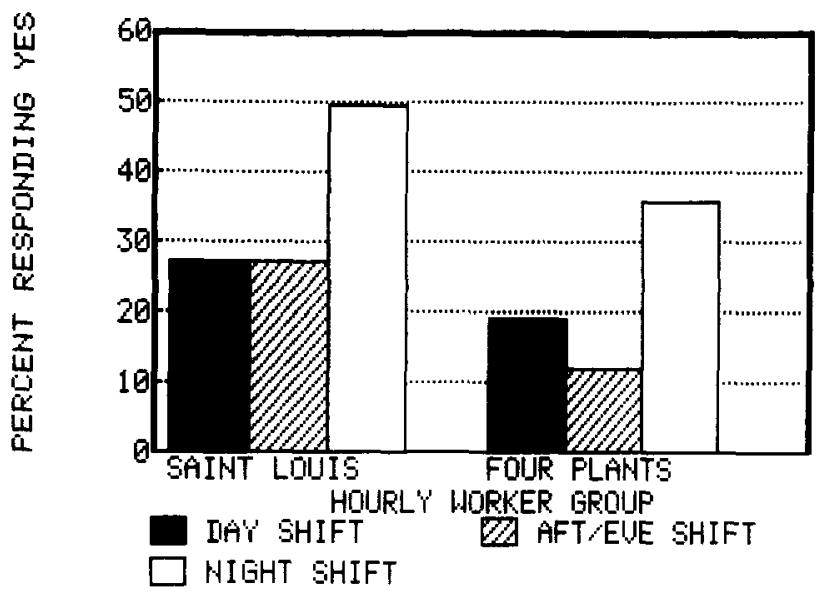

Figure 4. Percentage of hourly permanent shift workers on each shift in the Saint Louis and four-plant samples reporting that they often take naps during the workweek.

Workday napping. Workers were asked, "Do you often take naps during the work week?' Data from the response to this question are presented in Figure 4. For both samples, the percentage of workers responding "yes" to this question is highest for night-shift workers. The incidence of affirmative response in the two nightshift groups is higher than that of any other group.

\section{Comparison of Between-Plant Survey Data}

Age. A survey of the mean reported age of the hourly workers in each of the four plants was carried out. One of the more interesting findings was that the mean age of workers in Plant D is 10.8 years older (average is about 42) than those in Plant $C$, but only 1.76 years older than those in the Saint Louis sample.

Female workers. Each plant shows a different distri-

\section{REPORTED SLEEF' LENGTH}

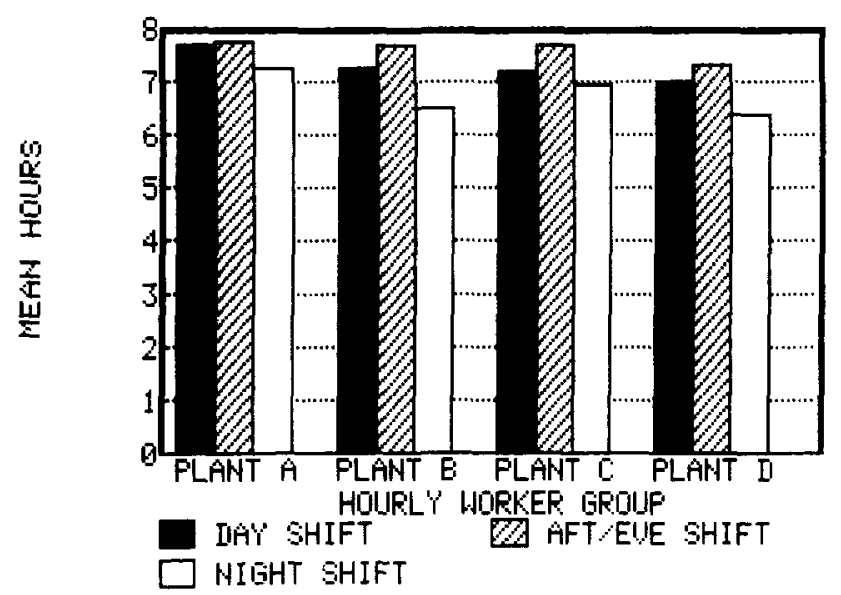

Figure 5. Mean reported workday sleep length in hours for the permanent shift workers on each shift for each of the plants in the four-plant sample.

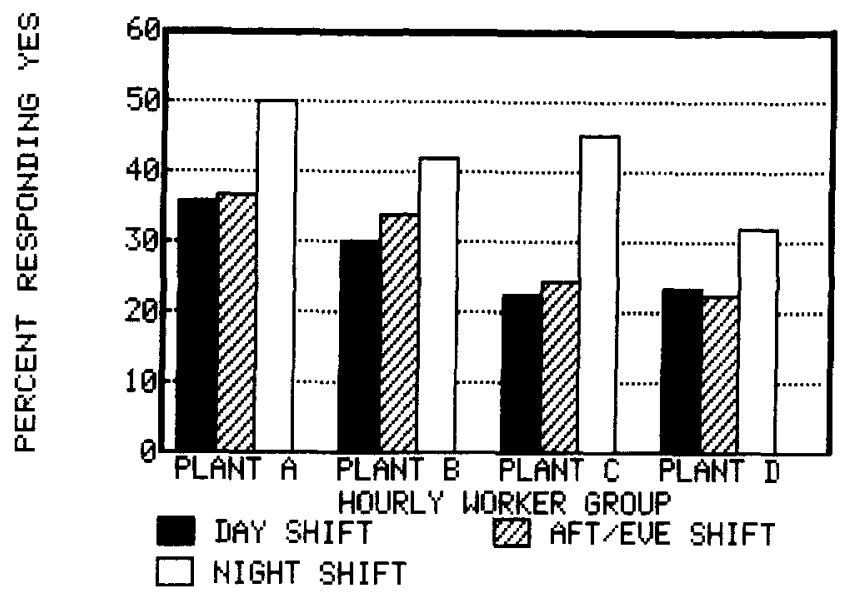

Figure 6. Percentage of hourly permanent shift workers on each shift for each of the plants in the four-plant sample who report difficulty in falling asleep or staying asleep.

bution of female workers across shifts. Two differences are of special note. First, Plant $C$ has a lower percentage of female workers in each of the shift groups than any shift group in any other plant. (The average over three shifts is $8 \%$.) Second, the night shift in Plant $A$ has the highest percentage of female workers $(63.3 \%)$ for the shift groups in all four plants.

Marital status. For all four plants, the percentage of divorced or separated workers on the night shift was found to be greater than that on the day shift. The Plant $\mathrm{C}$ data showed a lower divorce or separation rate than any shift group in any other plant. However, as reported earlier, Plant $\mathrm{C}$ also has the smallest number of females. Nightshift workers in Plant A showed the highest rate (33.3\%).

Workday sleep length. The finding that night-shift workers reported the shortest mean sleep length and af-

NAF DURING WORKWEEK



Figure 7. Percentage of hourly permanent shift workers on each shiff for each of the plants in the four-plant sample who report that they often take naps during the workweek. 
ternoon/evening-shift workers reported the longest sleep length appears to be quite robust within a plant, but differences between plants were observed (see Figure 5).

Difficulty sleeping. A high percentage of night-shift workers within each plant reported difficulty sleeping (see Figure 6). Differences between plants are notable. For example, $36 \%$ of Plant A day-shift workers and $32.1 \%$ of Plant D night-shift workers reported difficulty sleeping.

Workday napping. The percentage of workers reporting that they often take naps during the work week was highest for the night-shift groups within each plant. As Figure 7 shows, differences between plants are present. For example, the incidence of napping for Plant A workers is higher than that for each comparable Plant D shift group.

\section{Other Comparisons Between Plants}

The four plants showed large differences in a number of nonsurvey variables. For example, Plant $\mathrm{C}$ has more than 4.4 times as many hourly workers (nearly 700 total) as Plant A. Absenteeism rates were also surveyed (Figure 8), as were the average hourly earnings in each plant (Figure 9). The relationship between earnings and absenteeism for Plant $\mathrm{C}$ is striking.

\section{DISCUSSION}

The data indicate that the survey methods developed are acceptable to workers, yield findings in keeping with previous studies, and detect plant differences of interest in the selection of new work systems. In three of the four plants, the survey response rates were $95 \%$ or greater. This high response rate allows one to be confident that the results are not significantly distorted by sampling errors. Workers are interested in expressing their preferences and needs. They do provide representative and quantifiable information when it is gathered in a respectful and confidential manner.

The variables presented are only a small selected sam-

ABSENTEEISM RATE

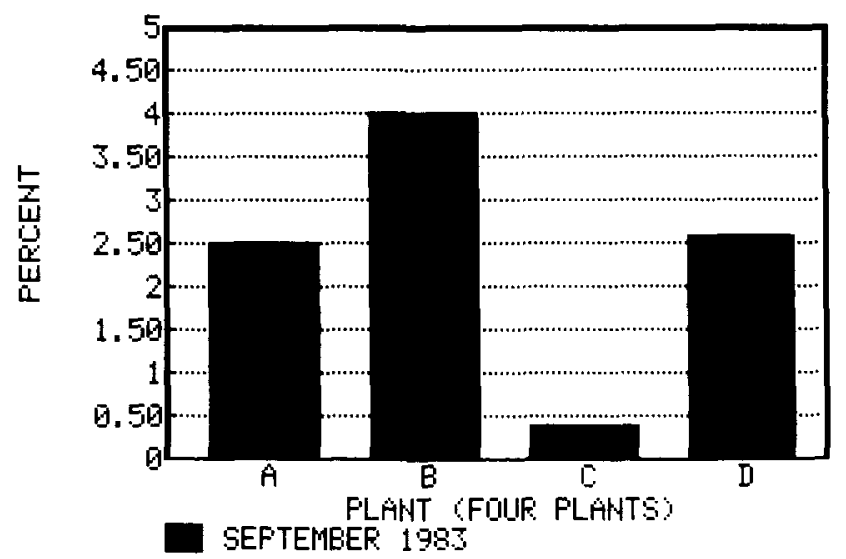

Figure 8. Absenteeism rate for hourly workers in each of the plants of the four-plant sample. (Data supplied by employer.)
ANERAGE HOURLY EARNINGS

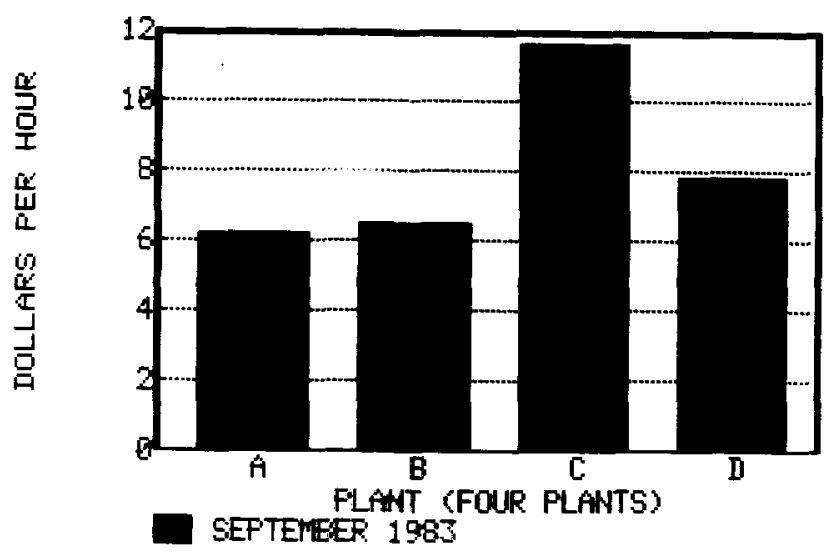

Figure 9. Average hourly earnings in dollars for hourly workers in each of the plants of the four-plant sample. (Data supplied by employer.)

ple of the survey data collected. Concentration on sleep behavior variables is appropriate because the effects of night work on these variables is well established. A number of independent studies show that night-shift workers sleep less and at different times of day than directly comparable workers on other shifts (Tepas, 1982b, c). These sleep differences are correlated with performance decrements (Tepas, Walsh, Moss, \& Armstrong, 1981) and are potential correlates of health problems (Tepas, 1982a).

Given these findings, one can argue that sleep variables are key indices that should be monitored and measured in all performance studies. It is equally important to note that there are preferred ways of gathering this information (Armstrong, Tepas, Canning, \& Lezotte, 1981; Tepas, Walsh, \& Armstrong, 1981). Negative results are easily obtained if the questions are improperly asked.

Shift-work issues are complex, and simple interpretation of findings may be misleading. The findings with regard to marital status are a good example. Divorce and separation rates are high for night-shift workers; this could be a manifestation of the stressful nature of night work. However, an equally attractive hypothesis suggests that single parents find night work a relatively easy solution to child care problems. Both of these hypotheses deserve further study. In either case, the fact that many night workers are divorced or separated highlights the problems of these workers.

Before recommending a new work-system shift scheme to a plant, the complexity of shift-work issues must be recognized by assessing a wide range of personal, social, and health issues. For example, we found that a high percentage (about $90 \%$ or more) of the workers in all four plants preferred to work one steady shift rather than rotate shifts. However, the reported shift-work history of these workers indicates that only $1.1 \%$ of both the hourly and salaried workers have worked rotating shifts. Thus, the preference for steady shifts may be a manifestation of the fact that these workers have little experience with rotating shifts, or that rotating shifts are less satisfactory. 


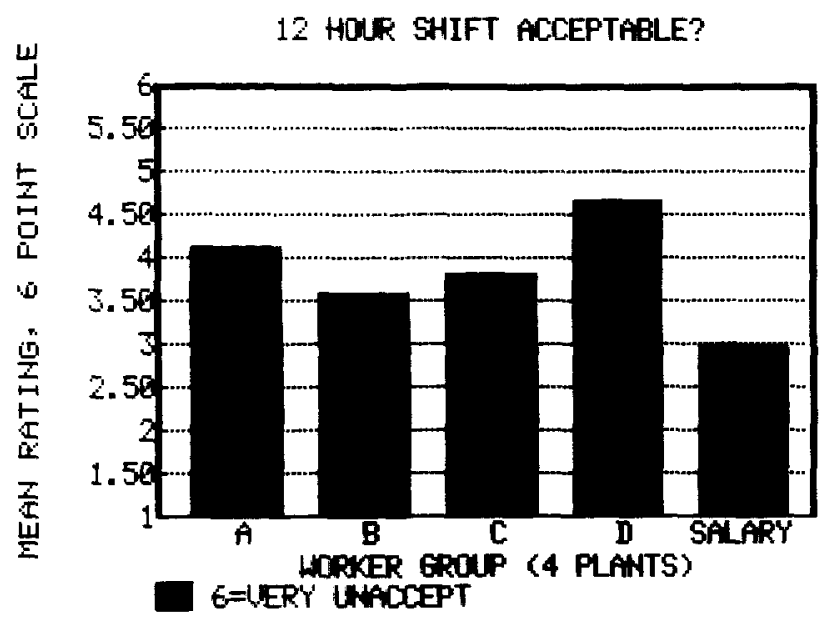

Figure 10. Mean acceptability of 12-h workdays for hourly workers in each plant and the salaried workers in all four plants. (Same worker groups as in Figure 11. A 6-point scale was used with 1.0 indicating very acceptable and 6.0 indicating very unacceptable.)

Figure 10 shows worker ratings of the acceptability of 12-h shifts. Hourly workers in Plant D rate 12-h shifts as more unacceptable than do workers in the other plants. In this case, the shift-work history of hourly workers in Plant D indicates that $53.1 \%$ have worked 12 -h shifts. These plants also differ in factors such as worker age and sex. Thus, it is difficult to suggest that this negative rating is totally related to $12-\mathrm{h}$ shift-work inexperience.

It has been suggested that 12 -h shifts may promote moonlighting (i.e., working at other jobs; Tepas, 1985). It follows that it may not be appropriate to recommend 12-h shift systems for a plant that already has a large number of individuals who moonlight. Figure 11 shows that the plants differ widely in the rate at which the respondents work at second jobs for additional income. Workers also were asked if they did most of the housekeeping at home. The results for this survey item are presented in

HAUE AHOTHER JOE FOR PAT?

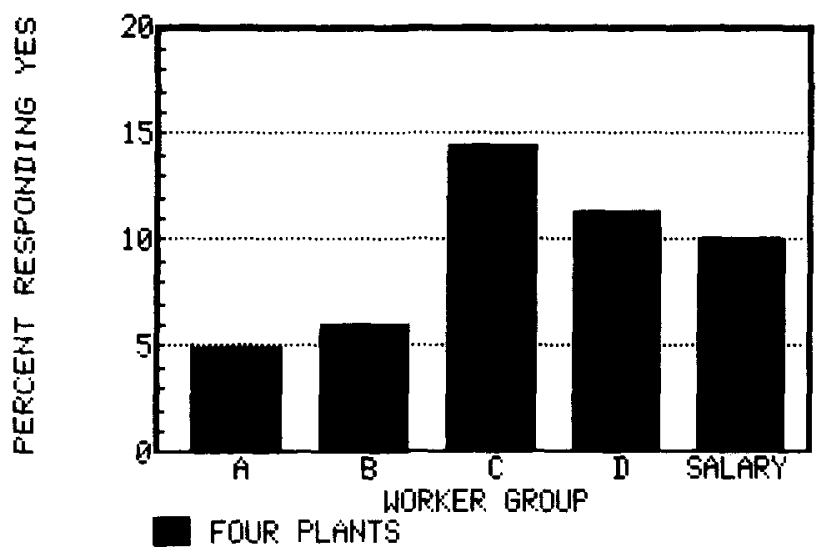

Figure 11. Percentage of permanent shift hourly workers in each plant and the salaried workers in all four plants who reported that they have another job for additional income. (Worker groups as in Figure 10.)
Figure 12. Again, the plants differ widely in the rate at which the respondents indicate that they do the housework. One can argue that housework, although not a paid job, is another form of a second job. Given this assumption, conclusions as to the degree of moonlighting in a given plant require a more complex analysis than simply asking a traditional question concerning employment on a second job.

Both of the above variables demonstrate the importance of using confidential third-party survey methods, since they involve variables on which employees might not provide employers with accurate data. The moonlighting rate for hourly workers in the four plants was $9.7 \%$, as compared to a $10.3 \%$ for the employer-independent St. Louis sample. Thus, some confidence in the moonlighting assessment for the four plants is appropriate.

Overall, the findings reported here are comparable to those in the Saint Louis study. The Saint Louis data were obtained at union meetings and validated in the laboratory, interviews, and follow-up studies (Tepas, Gersten, Duchon, \& Carlson, 1984; Tepas, Walsh, \& Armstrong, 1981). In Saint Louis, we did not gather employer-identity information or involve employers in any way. Thus, it is quite reasonable to argue that the data obtained with the methods described in this paper are also credible in that they are comparable. All surveys in both studies were made by the first author, and the number of workers responding to the Work-Sleep Survey totals 3,557. Although numbers and experience do not assure quality, the clear impression is that the data are valid.

Given the complexity of shift-work problems, making recommendations for new shift systems, at the present time, may be more of an art than a science, with few absolute or universal recommendations currently available (Tepas \& Monk, in press). The use of standard survey items and large reference data bases is a good basic current scientific method. It is important that one recognize worker preferences, but it is equally important not to

\section{DO MOST OF HOUSEKEEFING?}

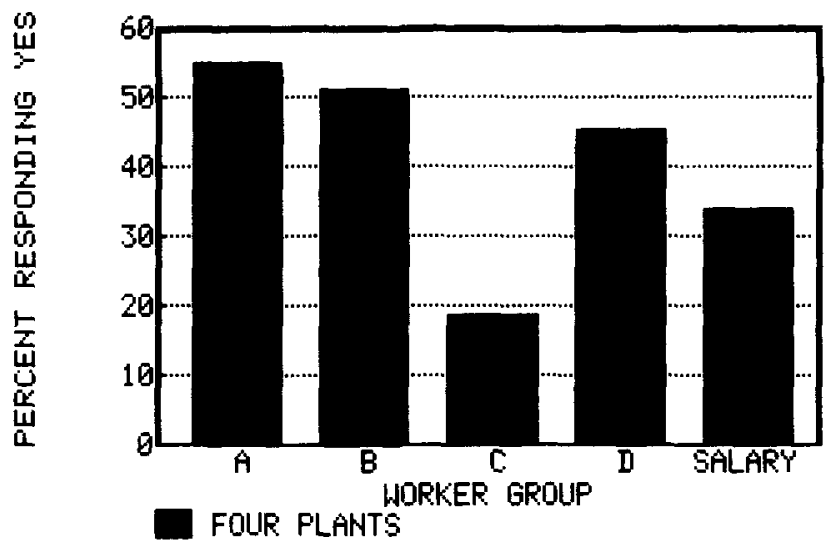

Figure 12. Percentage of permanent shift hourly workers in each plant and the salaried workers in all four plants who reported that they do most of the housekeeping at home. (Worker groups as in Figure 10.) 
recommend shift systems that conflict with known health issues or productivity requirements of the specific plant involved. Recognition of the complexity of shift-work problems, together with the demonstration of real differences between plants within the same general industry, supports the assumption that there are no simple or universal solutions as to how around-the-clock continuous shift work should be scheduled.

In developing recommendations for a given plant from a human factors viewpoint, the entire range of alternative work systems should be considered. Thus, before making recommendations, we considered work systems involving compressed workweeks, flexitime, work sharing, shortened workweeks, part-time employment, and other alternatives. In the typical plant, more than one shiftwork system is presented, with a list of potential advantages and disadvantages for each system. Final selection of a work system is made by management after deliberation with labor.

We always make two additional recommendations. First, we propose an educational program for workers which includes an explanation of how the new system works, a rationale for why the system was selected, and suggestions as to how individual workers might best cope with the social and health factors associated with shift work. Much to our dismay, this option has not been exercised to date. Second, a follow-up survey is recommended to evaluate the human factors effects of the new system after it has been in operation for some time. The objective of this second survey is to determine whether any additional work-system changes are needed, as well as to further assess the methods used to select and implement the system. At this point, one of these four plants has exercised this option.

It would appear that, in many industrial plants, the origin of the shift-work system in practice is unknown to those using it, and managers perpetuate the existing system to avoid the risk of change. Frequently, worker complaints about their work hours go unanswered, possibly contributing more to labor unrest than does dissatisfaction with wages (Imberman, 1983). The survey method outlined here is one way of assuring that workers' preferences, needs, and state are evaluated and presented to management. When the survey is properly offered, workers will participate. The resulting quantitative data is valuable to both management and labor as they consider new work-system options.

\section{REFERENCES}

Armstrong, D., Tepas, D. 1., \& Moss, P. D. (1980). Sleep reports from two samples of rotating shift workers. Sleep Research, 9, 267.

armstrong, D. R., Tepas, D. I., Canning, P. M., \& Lezotte, D. (1981). Sleep latencies: Watch what you ask and when! Sleep Research, $10,133$.

Gordon, G. C., Tepas, D. I., Stock, C. G., \& Walsh, J. K. (1979). Gaining access to shiftworkers through labor unions. Behavior Research Methods \& Instrumentation, 11, 14-17.

HoRne, J. A., \& OSTBERG, O. (1976). A self-assessment questionnaire to determine morningness-eveningness in human circadian rhythms. International Journal of Chronobiology, 4, 97-109.

Imberman, W. (1983). Who strikes-and why? Harvard Business Review, 61(6).

TEPAS, D. I. (1982a). Adaptation to shiftwork: Fact or fallacy? Journal of Human Ergology, 11(Suppl.), pp. 1-12.

TEPAS, D. I. (1982b). Shiftworker sleep strategies. Journal of Human Ergology, 11(Suppl.), pp. 325-336.

TEPAS, D. I. (1982c). Work/sleep time schedules and performance. In W. B. Webb (Ed.), Biological Rhythms, Sleep, and Performance (pp. 175-204). Chichester, England: Wiley.

TEPAS, D. I. (1985). Flexitime, compressed workweeks, and other alternative work schedules. In S. Folkard \& T. H. Monk (Eds.), Hours of Work. Chichester, England: Wiley.

Tepas, D. I., Gersten, A., Duchon, J. C., \& Carlson, M. L. (1984). A three-year follow-up survey of the sleep and health of experienced rotating shift workers. In I. E. Eustace (Ed.), Abstracts of the XXI International Congress on Occupational Health. Dublin: IOOC.

TEPAS, D. I., \& MoNK, T. H. (in press). Work schedules. In G. Salvendy (Ed.), Handbook of Human Factors/Ergonomics. New York: Wiley.

Tepas, D. I., Walsh, J. K., \& Armstrong, D. (1981). Comprehensive study of the sleep of shift workers. In L. C. Johnson, D. I. Tepas, W. P. Colquhoun, \& M. J. Colligan (Eds.), Biological Rhythms, Sleep and Shift Work. New York: Spectrum.

Tepas, D. I., Walsh, J. K., Moss, P. D., \& Armstrong, D. (1981). Polysomnographic correlates of shift worker performance in the laboratory. In A. Reinberg, N. Vieux, \& P. Anluer (Eds.), Night and Shift Work: Biological and Social Aspects. Oxford, England: Pergamon.

Walsh, J. K., Gordon, G. C., Maltese, J. W., McGill, W. L., \& TEPAS, D. I. (1979). Laboratory and field interview methods for the study of shiftwork. Behavior Research Methods \& Instrumentation, 11, 18-23. 